\section{DISCREPANCIES OF OPINION}

ON THE

RESPIRATION OF CARBONIC ACID GAS. NEW VIEWS OF THE VAPOUR OF BURNING CHARCOAL.

To the Editor of The LANCET.

Sir :-Having read in The Lancet for the present week some explanatory remarks by Dr. Golding Bird, upon his reported evidence on the inquest of Trickey, who was found dead in St. Michael's Church, in company with one of Messrs. Harper and Joyce's stoves, $I$ am induced to intrude a few more lines upon this very important subject.

Dr: Bird has stated the received opiuions of physiologists to be, that an atmosphere containing from $\mathbf{S}$ to 10 per cent. of carbonic acid gas, will, if respired for a long time, produce coma, and subsequently death, from spasmodic closure of the glottis.

Dr. Ure, in the third number of his "Dictionary of Arts, Manufactures, and Mines," published on the 1st of November last, has stated, under the article "Carbonic Acid," that if air contain more than 15 per cent. of this gas, it will be unfit both for respiration, and for the support of flame.

Dr. Turner, in his "Elements of Chemistry," informs us that a taper will not burn in a mixture of four parts of atmospheric air, and one part of carbonic acid gas ; $i$. e., when the air contains 20 per cent. of carbonic acid. We are also told that human beings cannot live in such an atmosphere.

Dr. Christison has retrograded a step, and quoted an exception to the very generally received opinion that a man may venture into an atmosphere contaminated by carbonic acid gas, provided the carbonic acid do not exceed the limit necessary for the combustion of a candle.

I cite a case, which occurred in my own neighbourhood, of a man descending into an abandoned coal-pit, in which ignited candles were repeatedly extinguished, and remaining in it for several minutes, until he successfully effected the object of his descent, viz., bringing to light the body of an unfortunate child, who had, through its youthful wantonness, been precipitated from a part of the old machinery.

Now all these different statements tend to bring each individually into discredit; and if these many discrepancies on this one subject are not sufficient, we have the opinion of Dr. Christison, that carbonic acid acts as a narcotic poison; and the subsequent assertion of Dr. Thomson, of Glasgow, that carbonic acid gas is not poisonous, but that it. causes death by suffocation, in the same manner as though the party were submersed under water.- (Vide Dr. Thomson's evidence on the trial of Mr. Muspratt, of Liverpool, for an alleged nuisance.)

Dr. Christison may, probably, have attributed the deleterious effects of the combustion of charcoal (as most other persons have done) to the carbonic acid evolved. I feel perfectly convinced that this common supposition is erroneous, and that the combustion of charcoal is attended by the evolution of some peculiar mephitic effluvia which have never yet been examined; and that, whether the charcoal be of the ordinary description, or whether it be "well burnt," by the continued application of a white heat for forty-eight hours, the same injurious vapours will be given off. It is to this point that I should wish to direct the attention of $\mathrm{Dr}$. Bird, whose natural acumen and cultivated talents are well suited for such a task. If charcoal be ever so well burnt and dried, it will, if ignited immediately after it is cold, give off much aqueous vapour, and some peculiar matter not visible to the eye unless it be condensed upon an interposing sur. face. This matter, when sublimed upon an iron plate, has the appearance of the bloom upon white grapes, and resembles it in colour. If a little of it be scraped from the plate, and heated in a glass tube, it will be found to be a hydrate. Moisture will appear at first, having an acid reaction; then a ring of white matter, resembling the volatilisation of arsenic, and, by continuing the heat, we get a second ring, very much like the last in appearance, but not ascending so high. What these substances are, remains to be proved. I detected them this very morning, and shall pursue the investigation.

When I reported to you the result of my own nocturnal experiment with the stove, which you kindly published in one of your November numbers, I said that I felt almost recovered. It was fully a week before the effects vanished; and, during the period of recovery, the smell of a candle that required snuffing, or of an extinguished lamp, was acutely arnoying to me. I should also have told you that, being accustomed to endure all the sulphureous and carbonic exhalations of an extensive glass manufactory, and also of vitriol, sulphate of soda, and alkali works, I am not so susceptible of annoyance from gaseous emanations as many other folks. A lady, who was on a visit at my residence, thought it fit one day to include the very stove which I have already described in her dressing-room, whilst she was preparing herself to dine. She had been about half an hour in this little apartment, which contained about 800 cubic feet of air, when she was seized with vertigo and faintness, and rendered perfectly unfit to make her appearance down stairs during the whole evening.

In this case, as in my own, the carbonic acid could have amounted to so small an excess above the ordinary atmospheric standard that it would be superlatively ridiculous to ascribe the consequences to the respiration of carbonic acid. Begging pardon for being so tedious, believe me, very truly yours,

Charles Thornton Coat
Wroxall, near Bristol, Dec. 1,1838 . 